\title{
طريقة Fishbowl لترقية ههارة الكلام بمدرسة هاشم أشعري المؤسطة النهضية سداتي سيدوارجو
}

\author{
Siti Qonita Latifah \\ Universitas Islam Negeri Sunan Ampel Surabaya \\ Luthfiyahqonita9@gmail.com
}

\author{
Ali Wafa \\ Universitas Islam Negeri Sunan Ampel Surabaya \\ awafarsd@gmail.com
}

\begin{abstract}
Abstrak: Proses pengajaran bahasa Arab di MTs Hasyim Ash'ari Ash-Nahdiyyah Sedati Sidoarjo merupakan proses pembelajaran tradisional, dimana guru menggunakan metode ceramah untuk mengajarkan keterampilan kalam. latar belakang penelitian ini adalah guru tidak memiliki inovasi dan model yang sesuai, sedangkan dalam proses pembelajaran membutuhkan penggunaan teori belajar yang tepat sehingga siswa tidak merasakan kesulitan dan dapat memperoleh materi yang lebih efektif dan efisien. Penelitian ini menggunakan metode kuantitatif. Adapun metode pengumpulan data adalah: metode observasi, metode pengujian dan dokumen. Adapun sampel penelitian, itu adalah 22 siswa di kelas tujuh. Dari penelitian ini dapat diketahui adanya peningkatan keterampilan kalam pada siswa setelah menerapkan metode Fishbowl. dengan analisis yang diperoleh dengan uji-t: t_0 hasil adalah 9.088 dan tt adalah 1.720 karena t_0 lebih besar dari tt maka hipotesisnnya nol (Ho) ditolak dan hipotesis alternatif (Ha) dapat diterima.
\end{abstract}

Kata Kunci: Thariqoh fishbowl, maharah kalam, pengajaran bahasa Arab.

\begin{abstract}
Abstrack: The process of teaching Arabic in MTs Hasyim Ash'ari Ash-Nahdiyyah Sedati Sidoarjo is a traditional learning process, where the teacher uses the lecture method to teach speaking skills. The background of this research is the teacher does not have the appropriate innovation and model, while in the learning process requires the use of appropriate learning theories so that students do not feel difficulties and can obtain material more effectively and efficiently. This research uses quantitative methods. The data collection methods are: observation method, test method and document. As for the research sample, it was 22 students in seventh grade. From this study it can be seen an increase in kalam skills in students after applying the Fishbowl method. with the analysis obtained with the t-test: $t$ _0 results are 9,088 and tt is 1,720 because $t \_0$ is greater than tt then the hypothesis zero (Ho) is rejected and the alternative hypothesis ( $\mathrm{Ha}$ ) is acceptable.
\end{abstract}

Key Word: Thariqoh fishbowl, maharah kalam, Arabic teaching. 
إن اللغة العربية هي إحدى اللغات السائدة في العالم التي استخدها أكثر من مأتي ملايينإنسانا وتستخدم رسميا أكثر من عشرين بلدا في العالم.وهي إحدى اللغات العظمة التي لها شأن عظيم و مكانة في العالم.تعرف أيضا اللغة العربية لغة الإسلام و المسلمين منذ بداية الإسلام.فهيا نزل القرأن دستورا للمسلمين وبها تحدث خاتم الأنبياء و المرسلين.اللغة العربية أقدم لغة حياة في العالم،لم يعترفها التغيير و التبديل.فلا خطأ إذا أنزل الله أشرف رسالة بأنرف اللغات،أي اللغة العربية .

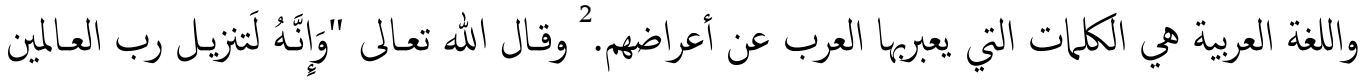

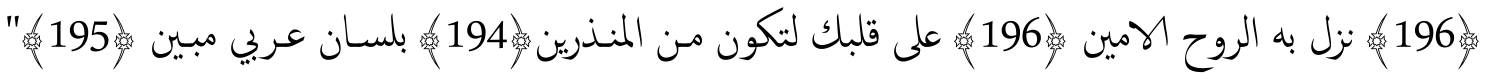
وفتّر الشـيخ عبد الرحمن بن ناصر السعدي هذه في تفسير الكريم الرحمن "أنّ بلسان عربي وهو أفضل الألسنه، بلغة من بُعثَ إلهم ،وباشر دعوته أصلا، اللسان البيّن الواضح. وتأمل كيف اجتمعت هذه الفضائل الفاحرة في هذه الكتاب الكريم، فإنه أفضل الكنـاب، نزل به أفضل الملايكة، على أفضل الخلق، على أفضل بضعة فيه وهي قلبه، على أفضل أمة أخرجت للناس، بفضل الألسنة وأفصحها وأوسعها، وهو الألسنة وأفصحها وأوسعها، وهو اللسان العربي المبين." وكما قال إمام الشافعي رحمه الله "إن فعلى كل مسلم أن يتعلّم من لسان العرب ما بلّفه جهده حتى يشهد به لا إله إلّا الله وأن محمد عبده ورسوله ويتلوا به كتاب الله..."4 تدريس اللغة العربيةهو العملية التعليمية التي يتمتوجيها إلىتشجيع وتوجيه وتطوير وتعزيز المهارات في اللغة العربية ، إما إيمابية أو سلبية ، وتعزيزموقف إيجابي.ينقسمتدريس اللغة العربية الىجانبين، هماعناصرها ومهاراتها. تدريسعناصرهاهوتدريس الأصول التيتنهصعليها اللغة العربيةمن الناحية النحوية أوالصرفية أوالصوتية أوالبلاغةأو المفردة أوالمعجمية. وأماندريسمهاراتهافيراد بهاتدريس المهارات الأربعة، وهيمهارة الاستماع والكلام والقراءة والكنتابة.

Azhar Arsyad , "Bahasa Arab dan Metode Pengajarannya",(Yogyakarta:Pustaka Pelajar:2003) hal .1,

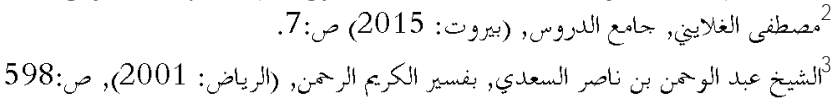

$$
\begin{aligned}
& 4
\end{aligned}
$$

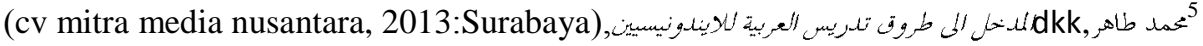


مهارة الكلام هي واحدة من أنواع المهارات اللغوية التي يجب تحقيقها في تعليم اللغة الحديثة من اللغة العربية.الكلام هو الوسيلة الأولى ليبني التفاهم المتبادل و التواصل المتبادل باستخدام اللغة العربية. في الحقيقة محارة الكلام هي إجادة اللغة المعقدة.في هذه الحالة و ترتبط هذه المهارة مع التعبير عن الأفكار و المشاعر مع الكلمات والعبارات الصحيحة.لذلك ترتبط الكفاءة ارتبطا وثيقا بمشكلة التفكير ما يكن قوله.إضافة إلى ذلك ترتبط الكفاءة ارتباطا وثيقا إلى النظام المعجمي و النحوي والللالي و الصوتي .كل هذه استطاعة تتطلب توفير بعض الكلمات و الجمل التي تتطابق مع الوضع المطلوب الذي تطلب الكثير من الكلام. 7 تهدف حمارة الكلام أن يكون الطلاب قادرين على التواصل بشكل جيد لفظيًا وبطبيعة الحال مع اللغة التي يدرسون بها. من الجيد والمعقول أن نقل الرسائل إلى الآخرين بطريقة مقبولة اجتاعيًا. ولكن بالطبع للوصول إلى مستوى ذكاء التواصل يتطلب أنشطة التدريب الدع الكافي.8 لتزقية أنشطة الطلاب في درس الكلام يمكن القيام بطرق مختلفة أو بوسائل مختلفة في عملية التعليم،نها بطريقة Fishbowl. لأهها تتطلب منهم ان ينشطوا و يشاروكاكل المشاركة في عملية التعليم. طريقة Fishbowl|إحدى من طرق المناقشة. هذه الطريقة هي إحدى من طرق التدريس والتعلم التي تقوم بها المعلم في المدرسة. في هذه المناقشة ، يمكن أن تحدث عملية التفاعل بين شخصين أو اكثثر من المشاركين ، وتبادل الخبرات والمعلومات وحل المشكلات ، كل ذلك لا يوجد طلاب نشطون كستمعين. 9 واعتماد على هذه المشكلات،فكتبت الكانب هذه الدراسة العلمية بموضوع "فعالية تطبيق طريقة Fishbowl لترقية محارة الكلام لدى طلاب الصف السابع بمدرسة هاشم أثعري المتوسطة النضية سداتي سيدوارجو".

Ahmad Fuad Effendy, Metodologi Pengajaran Bahasa Arab,(Malang:Penerbit Misykat,2005),hal.139

$$
\text { كزمجة من }
$$

ترجمة من: $7{ }^{7}$

Abd Wahab \& Mamlu'atul N,Memahami Konsep Dasar Pembelajaran Bahasa Arab,(Malang:UIN MALIKI Press,2011),Hal.88

Acep Hermawan.,Metodologi pembelajaran bahasa arab,(Bandung:PT Remaja Rosdakarya,2014),Hal.136

Ridwan Abdullah Sani,Inovasi Pembelajaran,(Jakarta:PT Bumi Aksara,2013),hal202. 8و جمة من: بوجمة من: 
كما عرفنا أن طريقة البحث ينقسم إلى نوعين و ها الطريقة الكيفية (Kualitatif) و الطريقة الكيّة (Kuantitatif). الطريقة الكيفية هي طريقة البحث التي تستغني عن الحساب و الأرقام العدديّة. وعكسها الطريقة الكميّة فأنها يكون فيها الحساب و الأرقام العدديّة. 10 أما طريقة هذا البحث هو الكمية التجريبية أي بحث مهدف إلى التحقيق المباشر في الأسباب والثأثنرات باستحدام الاختبار القبلي والبعدي. استخدمت في هذا البحث الثكل التجربيي هو تصميم مجمعة واحدة من اخختبار القبلي البعدي (one-group pretest-pesttest design). “Cooperative Integrated Reading And Composition” هذا البحث أن تعرف فعالية نموذج باستخدام وسيلة الكوميك البسيط في ترقية محارة القراهة و الكنابة لطلاب الفصل الثامن فى المدرسة المتوسطة الإسلامية الحكومية الأولى سورابايا. طريقة جمع البيانات البيانات هي كل ما احتاجتها الباحثة في هذا البحث. واستخدمت الباحثة طريقة جع البيانات المناسبة في هذا البحث. و الطريقة التي تستخدها الباحثة فيم يأتي: أولا: الملاحظة (Observasion). الملاحطة هي نشط الملاحظة والتمعن بتدوين البيانات أو المعلومات المناسبة بالبحث. ${ }^{12}$ تستخدم هذه الطريقة للحصول على البيانات عن مهارة القراءة و الكنابة لطلاب الفصل الثامن فى المدرسة المتوسطة الإسلامية الحكومية الأولى سورابايا. قد قامت الباحثة بهذه الطريقة لنيل المعلومات عن عملية تعليم اللغة العربية لطلاب باستخدام نموذج “Cooperative Integrated Reading And Composition”

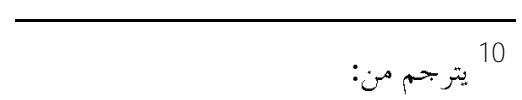
Sugiyono, Metodologi Penelitian Pendidikan Pendekatan Kuantitatif, Kualitatif R\&D, (Bandung Alfabeta, 2016), hal. 13 12 يتر جمم من: 11 نفر اجع، ص.110 Suharsimi Arikuntoro, Metodologi Penelitian (Jakarta: Bulan Bintang, 1996), hal. 229 
الباحثة قبلها مقرّر الملاحظة، فيه البيانات المحتاجة ستلاحظها الباحثة. وقد حضرت الباحثة الى تلك المدرسة مباشرة لمجح البيانات.

والنتيجة أن استخدامحا يجذب انتباه الطلاب ويثير حاستهم. نظرا من نثاط الطلاب لقراءة النص

الملكنوب و لكنابة الإنشاء في استعحال تلك الوسيلة عند عملية تعلم اللغة العربية. وهذه الوسيلة تسهل الطلاب في التعلم لأهه تستخدم اللغة البسيطة أو اليومية والصورة الملونة. واكثرثم سرعة الفهم، كما يتضح من قدرته على إجابة الأسئلة المقدمة فيما يتعلق بما تعلمه.نُانيا: الاختبار (Tes) ـ الاختبار هو بعض الأسئلة أو التارين أو الأدوات الأخرى المستخدمة لقياس المهارة والذكاء المعروفة، والقدرة أو الموهبة التي يمتلكها الأفراد أو المجموعات. ${ }^{13}$ هذا البحث استحدمت الباحثة طريقة الاختبار يعني الاختبار القبلي و الاختبار البعدي. أما الاختبار القبلي هو يجرى قبل بداية البرنامج التعليمي لمعرفة كفاءته. و أما الاختبار البعدي هو يجرى بعد انتهاء البرنامج التعليمي لمعرفة مدى التطور، التقدم و زيادة اللغوي الذي أنجزه الطلاب بعد استخدام البرنامج التعليمي. ونتيجة هذا الاختبار تقارن بنتيجة الاختبار القبلي لمعرفة مدى الفرق بينها..14في هذا البحث "Cooperative قبتل تطبيق نموذج استحت الباحثة طريقة الإختبار يعني إختبار قبلي (Pretest) Integrated Reading And Composition" “Cooperative Integrated Reading And Composition" بعد تطبيق نموذج (Posttest) باستخدام وسيلة الكوميك البسيط. واستعملت الباحثة هذه الطريقة لجمع البيانات عن كفاءة محارة القراءة و الكنابة لطلاب الفصل الثامن فى المدرسة المتوسطة الإسلامية الحكومية الأولى سورابايا. طريقة التحليل البيانات

“Cooperative Integrated Reading And رمز المأوية لتحليل البيانات عن فعالية نموذج باستخدام وسيلة الكوميك البسيط في ترقية محارة القراءة و الكتابة. التي حصلت عليها الباحثة بطريقة الاستيانات وهي : 13نفس المرجع، ص.193 ينت جمم من: M. Musfiqon, Panduan Lengkap Metodologi Penelitian Pendidikan, (Jakarta: PT. Prestasi Pustakarya, 2012), hal. 91 


$$
\begin{aligned}
& \mathrm{P}=\frac{F}{N} \mathrm{X} 100 \\
& \text { البيان : } \\
& \text { P النسبة الماؤية P } \\
& \text { F =كرار الاجابة } \\
& \text { N }
\end{aligned}
$$

\begin{tabular}{|c|c|}
\hline متمتاز & $11-1 \ldots$ \\
\hline جيد جدا & $V \cdot-\Lambda \cdot$ \\
\hline جيد & $09-79$ \\
\hline مقبول & $\sum \Lambda-O \Lambda$ \\
\hline مردود & $\varepsilon V-\cdot$ \\
\hline
\end{tabular}

أما التفسير والتعيين في تحليل البيانات المجموعة وتحقيق الإفتراض العلميّ. فيستعمل الباحث المقدار

الذي قدّمه سوهار سبيمي أريكونطا فيها يلي:

رموز المقارنة (T-Test)

وأما رمز المقارنة (T-Test) تستخدم الباحثة هذه لنيل المعرفة عن فعالية نموذج Integrated Reading And Composition” الكنابة لطلاب في الاختبار القبلي والاختبار البعدي، فتستعمل صيغة فيا يلي :

$$
t_{0}=\frac{M D}{S E_{M_{D}}}
$$

$$
\begin{gathered}
{ }^{16}: \text { البيان } \\
\text { المقارنة }=t_{0}
\end{gathered}
$$

Suharsimi Arikunto, Prosedur Penelitian Suatu Pendekatan Praktik, Edisi Revisi, (Jakarta :

Rineka Cipta, 2006), hal 246

$$
\text { : }
$$

$$
\text { 16 160نس المرجع، ص. 289 }
$$




$$
\begin{aligned}
& \text { المتوسطة (Mean ) من متغير X } \\
& M_{D=\frac{\sum D}{N}} \\
& \text { Y ومن X ع ع مد مختلفة من متغير } \\
& \text { N = جملة البيانات }
\end{aligned}
$$

SEML = الإخراف المعياري من متغير X ومن متغير Y والحصول على الصيغة :

$$
\begin{gathered}
S D_{D}=\sqrt{\frac{\sum D^{2}}{N}-\left(\frac{\sum D}{N}\right)^{2}}=S D_{D} \\
: S E_{M_{D}}=\frac{S D_{D}}{\sqrt{N-1}}
\end{gathered}
$$

“Cooperative Integrated Reading And عدم فعالية قبل وبعد نموذج $=\mathrm{H}_{0}$ Composition" “Cooperative Integrated Reading And وجود فعالية قبل وبعد نموذج = Ha Cبmposition" قبل الدخول في رمز الاختبار (T-Test) هناك العديد من الخطوات التي ينبغي القيام بها،

$$
\begin{aligned}
& \text { وهي : } \\
& \text { يطلب Mean of Different (M برمز : } \\
& M_{D=\frac{\sum D}{N}} \\
& \text { يطلب Standar Deviasi برمز : }
\end{aligned}
$$




$$
\begin{aligned}
& S D_{D}=\sqrt{\frac{\sum D^{2}}{N}}-\left(\frac{\sum D}{N}\right)^{2} \\
& \text { : Mean Of Difference }\left(\boldsymbol{S} \boldsymbol{E}_{\boldsymbol{M}_{\boldsymbol{D}}}\right. \text { ) من Standar Error يطلب (ج) } \\
& S E_{M_{D}}=\frac{S D_{D}}{\sqrt{N-1}}
\end{aligned}
$$

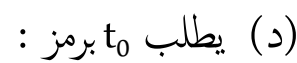

$$
\begin{aligned}
& t_{0}=\frac{M D}{S E_{M_{D}}} \\
& \text { to (ه) تقديم التفسير على }
\end{aligned}
$$

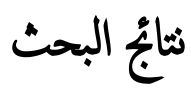

طريقة Fishbowl وتطبيقها

طريقة Fishbowl هي إحدى من طرق المناقشة. هذه الطريقة هي إحدى من طرق التدريس والتعلم

التي تقوم بها المعلم في المدرسة. في هذه المناقشة ، يمكن أن تحدث عملية التفاعل بين شخصين أو أكثر من المشاركين ، وتبادل الخبرات والمعلومات وحل المشكلات ، كل ذلك لا يوجد طلاب نشطون كستتمعين. تتطلب طريقة Fishbowlمساحة مفتوحة للمساعدة التزكيز على مناقشة المجموعة الكبيرة.ومع أنها تستغرق وقتا طويلا، فهي أفضل طريقة للجمع بين التميز من مناقشة المجموعة الكيرة و الصغيرة. 18 أما تطبيق طريقة Fishbowl فتم بأربع خطوات هي أولا ،يختار المعلم العديد من الطلاب الأذكياء لشرح مفهوم أو إجراء أو نشاط. وثانيا، يجيط الطلاب بالمعلم الذي يشرح لم المعلومات ، بينما يجيط الطلاب الآخرون بمجموعة الخبراء. وثالثا، بعد فهم المعلومات التي ينقلها المعلم، يقوم الطلاب الذين يصبحون متحدثين 
بشرح المادة أو الإجراء أو إظهار نشاط للطلاب الآخرين (وليس الخبراء) الذين يجيطون بهم. ورابعا، بعد تقديم المعلومات أو المناقشة ، يجري المعلم تقيياً للتحقق من فهم جميع الطلاب. 19 إن تطبيق طريقة Fishbowl في عملية التعليم من أجل تشجيع الطلاب على التفكير النقدي. ومن أجل تشجيع الطلاب على التعبير عن آرأهم بحرية. كما أنه تشجع الطلاب على المساهمة بأفكار هل لحل المشكلات الشائعة وأخذ إجابة بديلة واحدة أو عدة إجابات بديلة لحل المشكلة بناءً على دراسة متأنية مزايا طريقة Fishbowl تظهر في حفز إبداع الطلاب في شكل أفكار ومبادرات وانجازات جديدة في حل المشكلة. وتطوير احترام لآراء الآخرين. وتوسيع آفاق. وتشجيع التعود على المداولات للتوصل إلى توافق في حل المشكلة. وإدراك الطلاب أنه يككن حل المشكلات بطرق مختلفة وليس بطريقة واحدة. وتجعل الطلاب يدركون أنه من خلال مناقشة آراء بعضهم البعض بطريقة بناءة حتى يكن الحصول على قرارات أفضل. وتعويد الطلاب على الاستماع لآراء الآخرين رغز اختلافهم عن آرائه والتعود على التسامح. فعيوب طريقة Fishbowl تأتي في تلقى المشاركون في المناقشة معلومات محدودة. ويكن أن يتقن من قبل الناس الذين يجبون التحدث. وعادة ما يريد الناس مقاربة أكثر رسمية.

\section{محارة الكلام وخطوات تعلمها}

الكلام في أصل اللغة عبارة عن: الأصوات المفيدة، وعند متكلمين هو: المعنى القائم بالنفس الذي يعبر عيه بألفظ، يقول في نفي كلام، وفي اصطلاح النحاة: الجملة المركة المفيدة.أما النعريف الكلام الاصطلاحي للكلام فهو: ذلك الكلام المنطوق الذي يعبر به المتكلم عام في نقسه من هاجسه، أو خاطره، وما يجول بخاطره، وما يجول بخاكره من مشاعر وإحساسات، وما يزخر به عقله من رأي أو فكرة، وما يريد أن يزود به غيره من معلومات، أو نحو ذلك، في طلاقة وانسياب، مع صحة في التعبير وسلامة في الأداء. وقال عبد العليم إبراهيم في الكنابه الوجه الفنى لمدرّس اللغة العربية أقسام الكلام (التعبير ) إلى قسمين وهالالتعبير الشفوي والتعبير الكتابي. فالتعبير الشفوي هو ما يعرف باسم المحادثة أوالإيشاء الشفوي. تبد وأهمية في أنه أداة الابصال السريع بين الفرد وغيره، والنجاح فيه يجقق كثبرا من الأغراض الحوية في الميادين الختلفة،

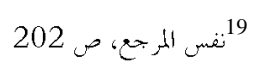


ومن مشكلاته في الميدان المرسى مزاحة اللغة العلمية، وغلها على ألسنة البلاميذ، وللتعبير الشفوي صور كثيرة، فنها التعبير الحر. والتعبير عن الصور التي يجمعها التلاميذ، أو بعضها عليهم المعلم، أو الصور التي بكتب القراءة. والتعبير الشفوي عقب القراءة، بالمناقشة والتعليق والتلخيص والإجابة الأسئلة. واستخدام القصص في التعبير بالصور الآتية. وحديث التلاميذ عن حياتهم ونشاطهم داخل المدرسة وخاربجا (حصص الألعاب، والرسم، والأشغال، والحفلات، والرحلات، والمباريات، ونخو ذلك). أما التعبير الكنابي فهوما يعرف باسم الإنشاء التحريري. هو وسيلة الاتصال بين الفرد وغيره، من تفصله عنه المسافات عنهم المسافسات الزمانية أوالمكانية، والحاجة إليه ماسة في جميع المهن، ومن صوره: أولا، جمع الصور والتعبيرالكتابي عنها، وعرضها في الفصل، أو في معرض المدرسة. وثانيا، الإجابات التحريرية عن الأسئلة عقب الثراءة الصامتة. وثالثا، تلخيص القصص والمضوعات المقروة أوالمسموعة. ورابعا، ثكملة الثصص الناقصة، وتطأى ويل القصص الموجزة. وخامسا، تأليف قصص في غرض معين، أو في عرض يختاره التبميذ. وسادسا، تحويل الثصة إلى حوار تمثيل. وسابعا،كتابة المذكات واليوميات والتقارير. وثامنا، كتابة الرسئل للاستئذان في زيارة الأماكن المختلفة، أو للدعوة إلى حفلة، أولتئدية واجب اجتماعي في مناسبات الشكر ، أو التهنئة، أو العزية، أو نحو ذلك من الأعراض الحيوية. وتاسعا، الكتابة في الموضوعات الأخرى احسية أو المعنوية، التي أشرنا إليها في صور التعبير الشفوي، على أن يتخيرها المدرس مناسبة للنلاميذ، في النوحي الاجتماعية، والقومية، الاقتصادية، والأدبية ونخوها. وعاشرا، أعداد الكلمات لإلقائها في مناسبات مختلفة. وحادي عشرة، نشر الأبيات الشعرية. وثانية عشرة، كتابة محاضر الجلسات والاجتماعية. هناك أهداف كثيرة ومتنوعة من تعليم محارة الكلام، وأهداف الكلام تشترك مع أهداف اللغة العربية العامة، وهناك أهداف عامة للكلام يككن توضيحها 21 الأول، إقدار الأفراد على القيام بجميع ألوان النشاط اللغوي التي يتطلهها منهم الجمتمع، والتعود على النطق السليم للغة، وهذا يستدعى أن يتعلم الفرد فن اللغة وقواعدها، حيث يستخدم ألفاظ للدلالة على المعاني المتنوعة التي تزد في أثناء الكلام، وصوغ الكلام في عبارات صحيحة. والثاني، تمكن الأفراد من التعبير عا في نقوسهم أو عما يشاهدونه بعبارة سلمة. ونكون ذلك بتزويدهم بالمادة

$$
\begin{aligned}
& \text { 20.نس المراجع, ص } 150 . \\
& \text { "أمد فؤاد عليان, المهارات اللغوية ماهيتها وطرائق تدريسها, (الرياض: دار الملم), 1992, ص" } 94 .
\end{aligned}
$$


اللغوية، لتترق لغتهم، وتكون لدهم القدرة على توضيح الأفكار باستخدام الكلامات المناسبة، والأسلوب المناسب، وذلك لأن الألفاظ تحمل سحنات معنوية لا تنفصل عنها. والثالث، تواسيع دائرة أفكارهم، وذلك بإقدارهم على تنسيق عناصر الفكرة المعبر عنها بما يضفي عليها جالا وقوة تأثير في السامع، وإقدارهم على نقل وجتة نظر إلى غيرهم من الناس، والإبانة عها في النفس بتعيبر سهل مفهوم. والرابع، تعويد الأفكار على التفكير المنطقي، والتعود على السرعة على التفكير والتعبير ، وكيفية موابحة المواقف الطائرة والمفاجئة، وتعويدهم على تنظيم تعبيرهم عن طريق تدريبه على جميع الأفكار واستفائها، وترتيها ترتيبا منطقيا، وربطقيا، وربط بعضها ببعض. والخامس، القدرة على مواجة الآخرين، وتنمية الثقفة بالنفس، والإعداد للمواقف الحيوية التي تتطلب فصاحة اللسان، والقدرة على الارتجال، والتعود على الانطلاق في الحديث والطلاقة في النعبير عا في النفس بجرأة وصدق، وتنمية القدرة على الاستقلال في الرأي. والسادس، اتساع دائرة النكيف لمواقف الحياة، باعتبار أن الكلام يتضمن كثيرا منها: كالسؤال والجواب، والمباحثات، والمناظرات، وإلقاء التعليمات والتوجيهات، وإدارة الحوار والمناقشات، والتعليق على الأخبار وغير ذلك. والسابع، إتقان الملاحظة السلمة عند وصف الأشياء والأحداث وتنوعها وتنسيقها، فالفرد يدقق في كتاباته، ولكنه في كلامة لا يكن كلامه لا يككن مدققا بصورة جيدة، وهذا الإنطقان يجب أن يتصف بالسرعة المناسبة، مع انتقان يجب أن يتصف بالسرعة المناسبة، مع انتقاء الألفاظ المناسبة للمعاني، وكذا التراكيب والعبارات، والتزود بها، لأن المتكلم سيحتاج إلها في حياته اللغوية. والثامن، تهذيب الوجدان والشعور، وممارسة التخيل والابنكار، والتعبير الصحيح عن الأحاسيس والمشاعر والأفكار في أسلوب واضح راق ومؤثر.

هناك عدد من الخطوات التي يستخدما المعلم عندما يعلّم محارة الكلام22 للمبتدئين أي أن يبداً المعلم في مارسة التحدث بطريق يعطي الأسئلة التي ييبي عليها التلاميذ. وفي الوقت نفسه ، يُطلب من التلاميذ تعلم كيفية نطق الكلمات وتركيالممل والتعبير عن الأفكار. وللمتوسطين أن تعلم التحدث عن طريق لعب الأدوار وناقش الموضوع. ويككي قصة عن الأحداث التي يختبرها التلاميذ. وأنيحكي عن المعلومات التي سمعت من التلفزيون أو الراديو أو غيرها.

UIN ‘Memahami Konsep Dasar Pembelajaran BahasaArab، Mamlu’atul Ni’mah ${ }^{22}$ Abdul Wahab Rosyidi Maliki Press 2011. Hlm : 95 
ولمتقدمين، أن يختار المعلم فكرة لمارسة كلام، ويجب أن يكون الموضوع المختار ذا علاقة مثيرة مع حياة

التلاميذ. ويجب أن يكون الموضوع واضحا،ودعوة التلاميذ لاختيار موضوعين أو أكثر حتى يتمكن التلاميذ اختيارالموضوع ما يعرفونه.

\section{فعالية طريقة Fishbowl لترقية محارة الكلام}

إن إحدى شروط إنشاء التعلم الفعال هي إعطاء الكثير من الأساليب في النعلم، لأن إعطاء أسلوب

تعليم متنوع سيوفر حافزًا كيرا للطلاب، ويكن أن تكون طريقة خishbowl خيارًا لأن من طريقة المناقشة المختارة من قبل.لأنيتضمنطريقةFishbowlبعض النقاط التي وفقًا للشروط والأحكام بحيث يمكن أن تعمل عملية النعلم الفعال.

إضافة إلى ذلك ، واستنادا إلى رأي ابن خلدون، فإن أسهل طريقة للعمل هي استخدام اللسان

المناقشة والنقاش فيا يتعلق بالمشاكل العلمية.هنا هي طريقة الاقتراب من ما هو مرغوب فيه وتحقيق ما هو المقصود. ${ }^{23}$ لذلك ، فإن طريقة Fishbowl هذه مناسبة لترقية همارة الكلام لدى طلاب الصف السابع بمدرسة هاشم أشعري المتوسطة سداتي سيدوارجو.

قد طبّق الكانب هذه الطريقة Fishbowl لترقية محارة الكلام لدى طلاب الصف السابع بمدرسة هاشم أشعري المتوسطة النهضية سداتي سيدوارجو. وأما عملية تطبيق طريقة Fishbowl لترقية مهارة الكلام لدى طلاب الصف السابع بمدرسة هاشم أشعري المتوسطة النضية سداتي سيدوارجو.بمادة "النعريف بالنفس"، فنكون من ثلاثة خطوات منها المقدمة والأنشطة الرئيسية والنشاط الهائى، وهي كما يلي: تدخل المدرّسة إلى الصف السابع. في بداية الدرس تلقي المدرّة السّلام على الطلاب ثم يقرؤون الدعاء معا. لتأكيد من حضورالطلباب تنادى المدرّة الطلاب بكشف الحضور وتعارفت المدرّسة مع الطلاب. حضر جميع الطلاب عددهم 22 طالبافي هذا اليوم.وتسأل المدرّسة عن الحال الطلاب بقول "كيف حالكم ؟" وييبب الطلاب "الممدله بخير". تسأل المدرّسة عن الدرس في اللقاء الماضي، فياللقاء الماضي يبحثون عن موضوع 
"النعريف بالنفس" ثخ تشرح المدرّة عن أهدف تعليم محارة الكلام وأنشطة التعليم وفوائد في الحياة ثم توضيحطريقة Fishbowl لترقية محارة الكلام لدى طلاب الصف السابع بمدرسة هاشم أشعري المتوسطة النهضية سداتي سيدوارجو.

تغير المدرسة موضع جلوس الطلاب المى وضع دائرة.ثم تختار المدرسة بعض الطلاب للفرقة الأولى (كتحص المورد) و للفرقة الثانية (كالسامع).والفرقة الأولى تتكون من الطلاب الذين نتيجتهم في الاختبار القبلى ممتازا.دوّر الطلاب المدرسة التي تشرح المادة عن المبتدأ و الخبر و أمثلنه في الكلمة.وبعد ذلك تقول الفرقة الأولى الى الفرقة الثانية عن تعريف بالنفس وتشرح عن التزكيب تلك الكلمة.ثم تستمر لوقت الأسئلة والأجوبة. والخاتمة هي تعطي المدرسة الإختبار البعدي لمعرفة كفاءة الطلاب وتكرر المدرسة بالتخليص.وتأثير المدرّسة الطلاب على فهم المواد الآتية .وتتنم المدرّسة بقراءة المحدلله رب العلمين والدعاء بعد التعلم معاثم القاء السلام. استخدم الكاتب طريقة الإختبار يعني اختبار قيلي، قبل استخدام طريقة Fishbowl الإختبار بعدي بعد استخدامحا. وتلك الإختبارات تستخدم لمعرفة فعالية تطبيق طريقة Fishbowl لترقية محارة الكلام لدى طلاب الصف السابع بمدرسة هاشم أشعري المتوسطة النضية سداتي سيدوارجو. أجرى الكاتب الإختبار التبلي والبعدي للحصول على معرفة فعالية نطبيق طريقة Fishbowl لترقية محارة الكلام لدى طلاب الصف السابع بمدرسة هاشم أشعري المتوسطة النهية سداتي سيدوارجو في اللوحة التالية:

وبعد أن نظر الكانب إلى نتيجة الاختبار القبلي والاختبار البعدي، فيظهر تطور كفاوة الطلاب في تدريس اللغة العربية بهارة الكلام.وجد الفرق بين نتاجُج الاختبار القبلي والبعدي. أما باعتبار على اللوحة السابقة تجد المسافة المتوسطة بين القيمة الاختبار القبلي والاختبار البعدي كما يلى:

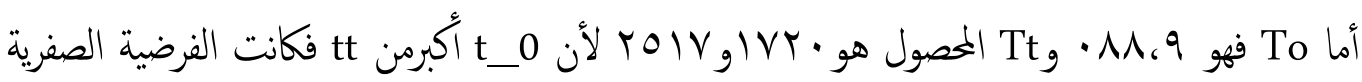
(Ho) مردودة والفرضية البدلية (Ha) مقبولة. بصرف النظر عن علامة السلبية (-) لأن فيه يحتسب الأرقام 
Fishbowl فقط. وهذا يدل على وجود فرق النتيجة في كفاءة الطلاب على محارة الكلام قبل تطبيق طريقة لترقية مهارة الكلام لدى طلاب الصف السابع بمدرسة هاشم أشعري المتوسطة سداتي سيدوارجو فظهر هناك وجود ترقية محارة الكلام باستخدام طريقة Fishbowl لترقية حمارة الكلام لدى طلاب

$$
\text { الصف السابع بمدرسة هاشم أشعري المتوسطة سداتي سيدوارجو. }
$$

وخلاصة الموضوع من ذلك إن نتاجُ الدراسة هي أولا، أن مارة الكلام لدى طلاب الصف السابع

بمدرسة هاشم أشعري المتوسطة النهضية سداتي سيدوارجو ناقص قبل تطبيق هذه الطريقة.تظهر نتائجهم في الاختبار القبلي وهي :بناء على البيانت الجمموعة ، 11\%من طلاب يحصلون على درجة " ممتاز"، هذه بالنظر على نتيجة المتوسطة في الاختبار القبلي. ويدل •9\% من طلاب يجصلون درجة "جيد جدا " ويدل

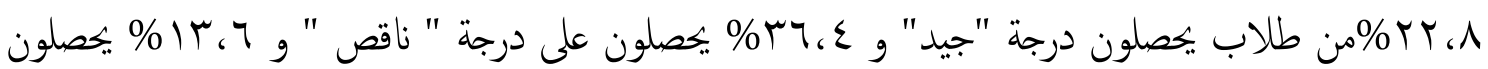
على درجة " قابح ".

وثانيا، إنتطبيق طريقة Fishbowl لترقية محارة الكلام لدى طلاب الصف السابع بمدرسة هاشم أشعري المتوسطة النهية سيداتي سيدوارجو بالخطوات كما يلي: 1) المقدمة، 2)تشرح المدرّسة عن أهدف تعليم محارة الكلام وأننطة التعليم وفوائد في الحياة ثم توضيحطريقة Fishbowl.و بعد ذلك تغير المدرّسة موضع جلوس الطلاب الى وضع دائرةثخ تختار المدرسة بعض الطلاب للفرقة الأولى (كثحص المورد) و للفرقة الثانية (كالسامع) للمناقشة.وتسأل المدرّسة الى الطلاب عن باب الذي بحث في المناقشة لمعرفة فهم الطلاب او لحصول هذه الطريقة.3) الاختتام. وثالثا، إن فعالية تطبيق طريقة Fishbowl لترقية مهارة الكلام لدى طلاب الصف السابع بمدرة

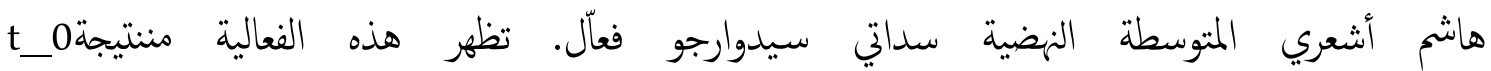

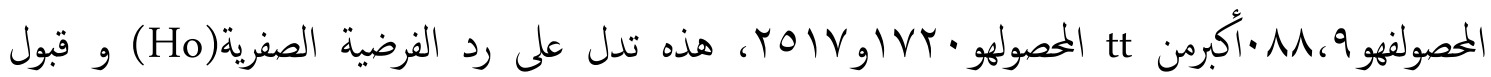
الفرضية البدلية (Ha). هذه النتيجة تدل على وجود ترقية مهارة الكلام بتطبيق طريقة Fishbowl في مدرسة هاشم أشعري المتوسطة النهية سداتي سيدوارجو. 
Abd Wahab \& Mamlu'atul N.2011. Memahami Konsep Dasar Pembelajaran Bahasa Arab. Malang:UIN MALIKI Press.

Al-Nâqah, Muhammad Kamâl. Ta'lîm al-lughah al-'Arabiyah li Națiqîn bi Lughâtin Ukhrâ. Makkah al-Mukarramah: Jâmah Ummul Qurâ.

Arsyad، Azhar.2003.Bahasa Arab dan Metode Pengajarannya. Yogyakarta:Pustaka Pelajar.

Dahlan‘ Djuariyah. 1992. metode belajar mengajar bahasa arab. surabaya : al ikhlas.

Effendy، Ahmad Fuad.2005. Metodologi Pengajaran Bahasa Arab. Malang:Penerbit Misykat.

Hermawan‘ Acep.2014. Metodologi pembelajaran bahasa arab.Bandung:PT Remaja Rosdakarya.

Ma'lauf, Louis. Al-Munjit fî al-lughah wa al-a'lâm. Beirut: Dâr al-Mushriq.

Rosyidi، Abdul Wahab.Mamlu"atul Ni'mah2011.Memahami Konsep Dasar Pembelajaran Bahasa Arab. Malang : UIN Maliki Press.

Sani، Ridwan Abdullah.2013. Inovasi Pembelajaran.Jakarta:PT Bumi Aksara.

Silbermen‘Dr.Melvin L. 2018. Active Learning 101 Cara belajar siswa aktif. Bandung:Penerbit Nuansa Cendekia.

Sugiyono.2015.Statistik Untuk Penelitian. Bandung : Alfabeta.

Sujono، Anas.2007. pengantar statistik pendidikan. Jakarta : Raja Grafindo Persada. Thâhir, Muhammad, dkk. Al-Madkhal Ilâ Țurûq Tadrîs al-'Arabiyah lil Indûnisîn.Surabaya: al-Jâmi'ah Sûnan Ampel Surabaya. 